\title{
FiM DA SOCIEDADE DO TRABaLHO OU IMPRECISÃO NO DEBATE?
}

\author{
Joel Paese \\ Professor de Teoria Sociológica nas \\ Faculdades integradas de Palmas/PR \\ E-mail: joelpaese@yahoo.com
}

\section{Resumo}

O texto analisa se é possível afirmar que a sociedade do trabalho encontra-se em un ponto terminal ou se estamos diante de análises reducionistas e imprecisas dos termos envolvidos no debate. A conclusão aponta para a permanência do trabalho como categoria fundamental à compreensão das ações individuais na sociedade, evidenciando não o fim da sociedade do trabalho, mas a sua transformação.

Palavras-chave: trabalho, sociedade do trabalho, desemprego, capitalismo.

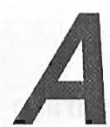

nalisar o fim ou a permanência da sociedade do trabalho passa, necessariamente, pela análise das formas de produzir mercadorias. Como afirma Antunes (1999, p.63), "entender a questão do trabalho implica, em primeiro lugar, entender a conformação do sistema produtivo." As modificações ocorridas no processo produtivo possibilitaram a emergência de teses que apontam para a perda de centralidade do trabalho na sociedade. Nosso objetivo é investigar em que medida a organização social ainda está relacionada a essa categoria.

Os anos 60 s marcam o início de transformações profundas no sistema capitalista, produzindo alterações na forma de produzir mercadorias e impactando decisivamente o mundo do trabalho e os atores envolvidos na sua dinâmica.

Segundo Pignon e Querzola (1980), as insatisfações dos operários em relação às suas condições de trabalho tornaram-se 
agudas. Absenteísmo, turnover, baixas de produtividade passaram a se constituir grande preocupação e impeditivo para a manutenção das taxas de acumulação de capital verificadas no período pós-2 $2^{a}$ Guerra Mundial.

Os princípios tayloristas e fordistas de organização do trabalho mostravam-se incapazes de manter os níveis crescentes de produtividade verificados no pós-guerra até a segunda metade dos anos $60 \mathrm{~s}$. Conforme Lipietz (1988, p.59), isto se devia ao fato de que as fontes de produtividade se reduziram "apenas à atividade dos engenheiros e técnicos que só podem aumentar a produtividade de todos os agentes através das máquinas mais complexas por eles concebidas".

Segundo Coriat (1988, p.16), um dos fatores responsáveis pela crise do taylorismo/fordismo em meados dos anos $60 \mathrm{~s}$, dizia respeito ao fato de que, dado o grau de sofisticação alcançado, a linha taylorista ou fordista se tornou, em parte, "contraproducente", pois "uma grande quantidade de tempos 'mortos' e de tempos 'improdutivos' eram gastos com técnicas complexas de balanceamento das cadeias de produção."

Diante de uma demanda com novas características (instável, volátil, diferenciada), que requer linhas "flexíveis" de produção para se adaptar rapidamente ao mercado, o taylorismo/fordismo não se mostrava adequado. Em decorrência houve a necessidade de

Renovar os suportes e os mecanismos clássicos para o desempenho dos ganhos de produtividade. A racionalização do tipo taylorista e fordista alcançou seus limites tanto sociais (instabilidades dos processos de trabalho baseados no parcelamento) quanto técnico-científicos (perda de balanceamento de encadeamento). (CORIAT, 1988, p.20-21).

Segundo Leite (1994, p.83), a necessidade de o capital de passar de uma base "rígida"| de produção e gerência da empresa para uma base "flexível" está fundamentada na "procura de novas formas de

1 Uma das características definidoras da automação rígida é a incorporação orgânica na máquina da memória da sequiência de operações, o que implica duas conseqüiências imediatas: 1) o maquinário não comporta modificações no tipo ou na sequiência 
garantia dos ganhos de produtividade e a flexibilidade da produção, como meio de adaptar o aparelho produtivo às novas exigências do mercado, que se tornara mais instável e competitivo com o aprofundamento da crise.

A esses dois desafios o capital responderá com a introdução da tecnologia microeletrônica, fundamentada nos princípios da integração ${ }^{3}$ e da flexibilidade, ${ }^{4}$ e de novas formas de gestão do processo de trabalho. Com isso buscou-se também a substituição do tipo de controle instituído pelo taylorismo por novas formas de controle social.

Conforme Xavier Sobrinho (1995), foi com o advento do microprocessador que a tecnologia de computação alterou sua trajetória de desenvolvimento, penetrando decisivamente no processo industrial: após duas décadas direcionada ao processamento de informações, deslocou-se para a atividade industrial. De acordo com Antunes (2000), é ilusão supor que as novas formas de produzir mercadorias eliminam o trabalho vivo. Elas o incorporam ao trabalho morto como componente necessário. O trabalho não desaparece na nova configuração do capitalismo, mas é transformado para se adequar às novas exigências do processo produtivo. Segundo ele,

A nova fase do capital, portanto, retransfere o "savoir faire" para o trabalho, mas o faz se apropriando crescentemente da sua dimensão intelectual, das suas capacidades cognitivas, procurando envolver mais forte e intensamente a subjetividade operária. Mas o processo não se restringe a essa dimensão, uma vez que parte do saber intelectual é transferido para as máquinas informatizadas, que se tornam mais inteligentes, reproduzindo parte das atividades a elas transferidas pelo saber intelectual do trabalho. Como a máquina não pode suprimir o

das operações realizadas e 2) qualquer alteração nesse sentido exigiria a entrada em ação de uma nova múquina.

2 A produção é flexível quando, sem necessitar de alteração física na base técnica, podem-se produzir elementos diferentes com mudanças ou melhoramentos do produto, mesmo radicais. Nesse último caso, exige-se que os equipamentos possam ser reutilizáveis sem a necessidade de intervalos excessivamente longos de readaptação.

${ }^{3}$ Com a utilização desse princípio chega-se a uma eliminação substancial dos tempos mortos na produção.

${ }^{4}$ Esse princípio corresponde ao que foi dito na nota 2 sobre produção flexível. 
trabalho humano, ela necessita de uma maior interação entre a subjetividade que trabalha e a nova máquina inteligente. [...] Portanto, em vez da substituição do trabalho pela ciência, ou ainda da substituição da produção de valores pela esfera comunicacional, da substituição da produção pela informação, o que se pode presenciar no mundo contemporâneo é uma maior inter-relação, uma maior interpenetração entre as atividades produtivas e as improdutivas, entre as atividades fabris e de serviços, entre atividades laborativas e as atividades de concepção, que se expandem no contexto da reestruturação produtiva do capital. O que remete ao desenvolvimento de uma concepção ampliada para se entender sua forma de ser do trabalho no capitalismo contemporâneo, e não à sua negação. (ANTUNES, 2000, p.9).

\section{Tecnologia e emprego}

Como é sabido, se por um lado o aumento de produtividade, causado pelo uso de novo maquinário, configura-se um fator poupador de mão-de-obra, causando desemprego, por outro, quando o trabalhador produz em escala maior, necessita-se de maior volume de matérias-primas, cuja produção requer o emprego de operários.

A utilização de novo maquinário, incorporador de novas tecnologias, gera compensações em termos de nível de emprego. De acordo com Salm (1984), se até o presente momento a literatura mostrou que novas tecnologias não necessariamente impactaram de forma negativa o emprego, pela primeira vez na história vislumbra-se um desvio de rota. A penetração de inovações tecnológicas, tanto na produção de bens como nos serviços e no setor terciário (bancos, escritórios, etc.), tende a gerar um efeito líquido negativo sobre o nível de emprego.

Num estudo sobre a relação entre produtividade e emprego industrial no Brasil, Cacciamali e Bezerra (1997) identificam que a partir de 1992 a produção industrial voltou a crescer, mas o emprego da mãode-obra não. De acordo com o estudo, nesse caso prevaleceu o uso mais disseminado das inovações que excluem o trabalhador do processo produtivo nas fábricas. 


\section{Guadro 1}

Taxas Médias Anuais de Crescimento do Produto, do Emprego e da Produtividade do Trabalho, Segundo Gêneros Industriais no Brasil, 1990-1995 (\%)

\begin{tabular}{l|c|c|c|c} 
Gêneros & $\begin{array}{c}\text { Produção } \\
\text { Industrial }\end{array}$ & $\begin{array}{c}\text { Pessoal } \\
\text { Ocupado }\end{array}$ & $\begin{array}{c}\text { Horas Pagas } \\
\text { naProdução }\end{array}$ & $\begin{array}{c}\text { Produtividade } \\
\text { Hora }\end{array}$ \\
Ind. de Transformação & 2,38 & $-4,79$ & $-5,33$ & 8,15 \\
Ind. Mecânica & 1,97 & $-3,79$ & $-4,30$ & 6,56 \\
Ind. Metalúrgica & 1,96 & $-4,78$ & $-4,64$ & 6,93
\end{tabular}

Apesar de haver associação entre desemprego e utilização de novas tecnologias, como fica evidenciado pelos dados acima, a análise da causalidade entre essas duas variáveis deve ser controlada por outros fatores a fim de evitarmos interpretações espúrias. Mattoso (1987) observa dificuldades quando se quer estabelecer vínculos entre processos de automação e mercado de trabalho. Segundo ele, a relação torna-se complexa em vista do conjunto de fatores de níveis distintos, especialmente os de ordem estrutural e conjuntural mesclados a problemas de ordem econômica, política e de organização social.

Embora as fortes evidências que apontam para a generalização do desemprego, em muito devido às transformações na forma de produzir mercadorias, verificadas no capitalismo a partir dos anos $60 \mathrm{~s}$, não podemos afirmar que isso leve a um sentimento individual de perda da relevância social da condição de trabalhador. É disso que trataremos a seguir.

\section{0 mundo do trabalho como universo prático-simbólico: o tema da centralidade do trabalho}

Ao abordarmos a problemática da centralidade do trabalho na estruturação da sociedade capitalista, não podemos deixar de discutir a tese de Offe (1994), segundo o qual essa centralidade desapareceu.

Dois mecanismos são apontados por ele como garantidores de que "o trabalho desempenha um papel central na organização da 
existência individual": 1) o trabalho como um "dever"; em nível da integração social; 2) o trabalho como "necessidade", em nível da integração do sistema. No primeiro caso o trabalho se constitui o elemento central de "uma vida honesta e moralmente boa. No segundo, é meramente uma "condição de sobrevivência física" (OFFE, 1994).

Segundo Offe (1994, p.184), a capacidade de a ética do trabalho e orientar as ações dos indivíduos na sociedade está hoje enfraquecida, pelo fato de que ela só pode funcionar a medida que o exercício de um trabalho pelo indivíduo possibilita seu reconhecimento pelo grupo social como uma pessoa que atua moralmente. Por outro lado, segundo ele, existem "muitas dúvidas se, e em que áreas do trabalho social, esta pré-condição está sendo satisfeita hoje em dia."

As conseqüências da estigmatização moral e da autoestigmatização, causadas pelo desemprego ou afastamento involuntário da vida de trabalho, desaparecem progressivamente à medida que estes dois elementos se tornam crescentes, o que impossibilita considerá-los responsáveis pelo fracasso ou culpa individual.

Sem dúvida, a capacidade de coerção que a moralidade vinculada ao "dever" de trabalhar exerce é minimizada pela difusão do desemprego. Mas isso não implica a sua irrelevância para a análise das trajetórias dos desempregados no mercado de trabalho. Notadamente, no caso dos provedores de família, em particular numa sociedade cuja sobrevivência dos indivíduos depende da prática de alguma atividade laboral, o exercício do trabalho é associado a uma conduta honesta e moralmente recomendável, tornando-se um elemento fundamental na orientação de suas condutas na sociedade

Segundo Offe (1994), um Estado do Bem-Estar desenvolvido, numa sociedade industrial avançada, tende a retirar parcelas crescentes da força de trabalho da condição de trabalhadores assalariados. A partir daí, não estranha que ele identifique uma diminuição do volume de trabalho integrando o cotidiano da vida destes indivíduos e um aumento do número de experiências vivenciadas fora do mundo do trabalho, capazes de se constituírem num condicionador substituto, em relação à ética do trabalho, da orientação de suas vidas no meio social.

Um exemplo é a legislação de seguro desemprego, a qual permite a manutenção de um padrão de vida para os desempregados, semelhante 
àpuele do periodo de emprego. Ou seja, é possível uma estratégia de sobrevivência que não se limita à necessidade de estar exercendo algum tipo de trabalho, especialmente sob a forma de emprego.

Situação como esta dificilmente pode ser característica de países con um Estado do Bem-Estar praticamente inexistente. Nestes locais predomina a jornada de trabalho maior que nos países descritos por Offe (1994), bem como um seguro desemprego de tempo reduzido e que não proporciona ao ex-empregado a manutenção do padrão de vida que possuía.

Tende a predominar nesses locais a necessidade do indivíduo cumprir uma extensa jornada de trabalho a fim de poder viabilizar o próprio sustento e da famúlia, reduzindo suas experiências vivenciadas àquelas do local de exercício de sua ocupação. Além disso, o vínculo permanente a algum tipo de trabalho, preferencialmente sob a forma de emprego, passa a se constituir a única possibilidade de obter as condições mínimas que garantam a sobrevivência, tanto do trabalhador como de sua família, quando é o caso.

A partir daí, pode-se afirmar, então, que o argumento de Offe (1994), a respeito de um declínio da ética do trabalho, como elemento capaz de ser parâmetro de moralidade no meio social, perde sua força quando aplicado a outros espaços, que não aqueles governados por um "Estado do bem-estar desenvolvido", numa "sociedade capitalista industrial avançada".

A existência de outras sociedades, onde o permanente exercício de alguma forma de trabalho se constitui a única possibilidade legítima de proporcionar inserção social, autoriza-nos a defender o posicionamento segundo o qual o trabalho permanece como uma referência fundamental para a orientação das condutas individuais no meio social. Assim sendo, sua condição moral na sociedade continua sendo avaliada a partir da execução ou não de um determinado trabalho.

Bernardes (1994) contesta os argumentos de Offe (1994) com relação à perda de centralidade da categoria trabalho na sociedade. Segundo ele,

1) os exemplos internacionais mostram que o que está ocorrendo é um redimensionamento ético e moral do trabalho, com sua virtual ascensão valorativa;

2) há uma revalorização do trabalho e uma perda de funcionalidade do paradigma taylorista nas novas condições de 
produção, através de um resgate da inteligência na produção, ao invés de uma desqualificação, a qual estaria associada não exclusivamente ao processo de trabalho, mas à própria exclusão dele;

3) com a proliferação, neste final de década, do desemprego e de postos de trabalho instáveis, mal remunerados e com vínculo tênue, uma vez fora torna-se mais difícil reinserir-se no sistema ocupacional. Isso significaria o risco de exclusão da própria sociedade do trabalho, estando desempregado.

Hirata apud Bernardes (1994), argumenta que com a introdução de novas tecnologias e novos padrões organizacionais, e a conseqüiente necessidade de operacionalizá-las, o lugar do sujeito e das relações intersubjetivas são absolutamente centrais. A mobilização psíquica do indivíduo, tornado sujeito do processo de trabalho, constitui-se a precondição mesma de toda atividade produtiva.

Hirata (1994) contesta a dimensão europocentrista da análise de Offe (1994), o que o levaria a argumentar no sentido da existência de um declínio da centralidade do trabalho na sociedade contemporânea. Segundo ela, isto se deve a algumas razões: uma definição extremamente restrita do trabalho, excluindo todo trabalho não diretamente produtivo e industrial, o que elimina o trabalho no setor de serviços até o trabalho doméstico; e o fato de que uma visão europocentrista não considera a divisão internacional do trabalho, que concentra cada vez mais nos países ditos "subdesenvolvidos" ou "semi-industrializados" as atividades intensivas em trabalho vivo.

A capacidade de orientação moral do sentimento do dever de trabalhar, de que nos fala Weber (1992), é analisada por Vera Pereira (1993). Em seus estudos, ela identifica presença de tal capacidade como condicionadora da auto-imagem do indivíduo diante do grupo social no qual está inserido, ao contrário do que afirma Offe (1994), como vimos anteriormente.

O desempregado é para si mesmo um 'alijado da sociedade', sua experiência pessoal leva-o a se ver como um não-ser, um indivíduo sem inserção social, um não-existente, mesmo que explicitamente se sinta adaptado a uma situação de carência material e dependência familiar. Os homens adultos, que antes sustentavam 
a família, sejam eles provenientes de camadas sociais altas ou baixas, tendem a se definir como 'marginais' sociais, condição que lhes traz culpa e vergonha. (PEREIRA, 1993, p.32).

Continuando, Pereira afirma que a referência para a autocompreensão do desempregado é, sem dúvida, a "moralidade" de uma "sociedade da produção, da mercadoria, do fazer". Nela, este indivíduo encontra-se "improdutivo" por um tempo freqüentemente imprevisível, que torna mais difícil o retorno a uma ocupação estável de assalariamento, quanto mais se prolongar o desemprego. Emerge daí o sentimento de exclusão social, de marginalidade, culpa e vergonha. À medida que todo indivíduo "precisa encontrar alguma solução para a sua inserção na sociedade, definir de algum modo uma identidade pessoal ou familiar" (PEREIRA, 1993, p.34), uma "ética do trabalho" constitui-se elemento capaz de responder positivamente a esta demanda.

A argumentação de Offe (1994), contrariamente a esse posicionamento, deve ser relativizada e mesmo questionada, especialmente quando aplicada a países fora da Europa, como afirma Hirata, nos quais existe uma sociedade do trabalho, produtora de mercadorias e configurada em moldes diferenciados.

A posição de chefe provedor é outro condicionante decisivo da trajetória desse indivíduo em sua busca de inserção num emprego. Ele orienta sua conduta a partir de uma "ética do provedor", ou seja, um conjunto de valores morais, estruturada a partir do "chefe provedor" Zaluar (1985). Segundo Sousa (1994), sendo responsável pela subsistência familiar, o chefe provedor constrói em torno de si a noção de "respeitabilidade" e "dignidade", a partir da qual delimita o campo da família organizada e do trabalho honesto, contrapondo-os à prática da transgressão social vinculada ao dinheiro fácil, advindo de roubos, tráfico de drogas, etc.

Sousa (1994), num trabalho sobre exclusão social, efetuado com trabalhadores da construção civil, faz uso dessa perspectiva analítica na sua investigação dos cotidianos de trabalho desses indivíduos. Ela verifica que realidades vivenciadas na família são transpostas para o mundo do trabalho. 
A partir da identificação dessa transposição, a autora conclui que os discursos desses trabalhadores revelam

A consciência da obrigação com o sustento familiar presente nos operários, fato que os leva até a aceitar humilhações e injustiças cometidas pelos chefes da produção muitas vezes calados, temerosos de que qualquer resposta possa resultar em demissão, tal como tradicionalmente tem ocorrido na indústria da construção civil. Neste sentido, a forte presença do dever moral parece configurar um ponto de sustentação dos trabalhadores no mercado de trabalho. (SOUSA, 1994, p.69).

Conforme a autora, o "sentimento individual do dever de chefe provedor" se traduz na "consciência da obrigação com o sustento familiar", o qual se transforma num "dever moral". Esse "sentimento" vincula-se ao exercício de uma atividade, sendo um emprego a modalidade preferencialmente escolhida. É comum verificar a submissão a qualquer tipo de trabalho ou condição de trabalho, em vista da "consciência da obrigação" do dever para com o provimento do sustento familiar. ${ }^{5}$

A literatura a respeito aborda a temática do comportamento do indivíduo no mercado de trabalho diante da necessidade de conciliar a posição de "provedor", o reconhecimento social dessa condição e a necessidade de reinserção em alguma forma de trabalho.

Segundo Telles (1992, p.65), as dificuldades de realização do modelo de "chefe provedor" acarretam instabilidades no interior do ambiente familiar. Isso vem a ocorrer, visto que tal indivíduo "se reconhece e é reconhecido pelos outros na medida em que, através de seu trabalho, garante a sobrevivência de seus familiares."

O reconhecimento da posição social do indivíduo no grupo familiar se relacionada ao exercício ou não de algum tipo de trabalho. Tal condicionamento é decisivo para a trajetória do "provedor" no mercado de trabalho. Ele empreenderá uma busca permanente de inserção em

\footnotetext{
${ }^{5}$ Devemos considerar que não são apenas aspectos morais, obviamente, que condicionam a busca de um emprego pelo chefe provedor, mas também a necessidade imediata de obter os meios de subsistência do grupo familiar.
} 
alguma forma de trabalho, a medida que esta se constitui o meio socialmente reconhecido que the possibilita prover a subsistência da fimmilial.

Pesquisando as trajetórias dos desempregados, Hirata e Humphrey (1989) ressaltam o condicionamento que o "senso de responsabilidade" exerce sobre o chefe provedor, ainda que outros integrantes da família trabalhem. Segundo eles

Mesmo quando havia no domicílio outros membros disponíveis para o trabalho, o provedor do sexo masculino era dotado de senso de responsabilidade em relação às finanças familiares. Quando indagados sobre sua experiência de desemprego, os operários casados tendiam a se concentrar sobre esta questão. A perda do emprego abala o status de provedor. Se outros no domicílio podem sustentá-lo financeiramente, isso tende a reforçar o sentimento de fracasso do marido. (HIRATA; HUMPHREY, 1989, p.87).

Num estudo que realizamos na região metropolitana de Porto Alegre com desempregados chefes de famúlia vinculados à indústria metal-mecânica, o trabalho sempre era mencionado nas entrevistas como fundamental para orientar as trajetórias desses indivíduos no mercado de trabalho.

De acordo com um dos entrevistados, "os filhos saberem que o pai não está trabalhando deixa ele desmoralizado perante os filhos, dá menos autoridade ao pai." Conforme outro entrevistado, "o desempregado é uma pessoa inútil [...] quando a pessoa não está trabalhando sente-se humilhada. Muitas coisas que deveriam ser feitas em casa, como consertos domésticos ou compra de móveis novos não é possível pois o marido está desempregado. Logo ele que tem essa obrigação."

Fica evidente que o trabalho permanece como elemento decisivo para a orientação das condutas individuais no meio social. Isso é reforçado quando se analisa o caso dos chefes provedores. A pressão sobre eles é maior ainda, em vista da necessidade de sustentar a famúlia.

Não podemos analisar a centralidade do trabalho tão somente sob o prisma da diminuição de empregos oferecidos pelas empresas ou

- Argumento que não se sustenta, como demonstra Antunes (2000). 
da eliminação da participação do trabalho vivo na produção. ${ }^{6}$ Esse é tão somente um dos aspectos a ser considerado. Devemos levar em conta a carga simbólica que envolve a condição de ser ou não ser trabalhador, vinculada à concepção do trabalho como um dever, perante o próprio indivíduo e os demais.

A sociedade do trabalho é um espaço multidimensional que, uma vez abordado de forma reducionista e apressada, pode conduzir o investigador a análises ilusórias. Enquanto o trabalho vivo for necessário no processo produtivo e a condição individual e social de ser ou não ser trabalhador, na sua dimensão simbólica, fizer diferença, teses que sugerem o fim da sociedade do trabalho não se sustentarão, se submetidas a análises empíricas mais rigorosas. Não estaremos diante do ponto terminal da sociedade do trabalho, mas tão somente da sua transformação.

\section{Referências Bibliográficas}

ANTUNES, Ricardo. Material e imaterial. Folha de São Paulo. São Paulo, 13 ago. 2000. Caderno Mais!

. O mundo do Trabalho em mutação. Estudos Leopoldenses, São

Leopoldo, v.35, n.155, p.59-72, 1999.

BERNARDES, Roberto. Trabalho: a centralidade de uma categoria analítica.

São Paulo em Perspectiva, São Paulo, v.8, n.1, p.33-41, 1994.

CACCIAMALI, Maria Cristina; BEZERRA, Lindberg de Lima. Produtividade e emprego industrial no Brasil. Revista Brasileira de Economia, Rio de Janeiro,v.51, n.1, p.77-91, Jan./Mar., 1997.

CORIAT, Benjamin. Automação programável: novas formas e conceitos de organização da produção. In: Schmitz, Hubert; CARvalho, Ruy de Quadros (Orgs.). Automação, competitividade e trabalho: a experiência internacional. São Paulo: Hucitec, 1988.

HIRATA, Helena. Da polarização das qualificações ao modelo da competência. In: FERRETTI, C. J. et al. (Org.). Novas tecnologias, trabalho e educaf̧ão: um debate multidisciplinar. Petrópolis: Vozes, 1994. 
HIRATA, Helena; Humphrey, John. Desemprego oculto pelo trabalho precário: operários industriais na grande São Paulo. São Paulo em Perspectiva, São Paulo, v.3, n.1/2, p.84-91, 1989.

LEITE, Márcia de Paula. O futuro do trabalho: novas tecnologias e subjetividade operária. São Paulo: Scritta, 1994.

LIPIETZ, Alain. Miragens e milagres: problemas da industrialização no terceiro mundo. São Paulo: Nobel, 1988.

MATTOSO, Jorge. Impactos da automação sobre o emprego e o trabalho. In: ENCONTRO REGIONAL, 1987, Porto Alegre. Impactos da automação sobre o trabalho. Porto Alegre: SEACT, 1987.

OFFE, Claus. Capitalismo desorganizado: transformações contemporâneas do trabalho e da política. 2.ed. São Paulo: Brasiliense, 1994.

PEREIRA, Vera Maria Cândido. Quem são os desempregados para a sociologia? Cadernos de Sociologia, Porto Alegre, número especial, p.27-37, 1993

PIGNON, Dominique; Querzola, Jean. Ditadura e democracia na produção. In: GORZ, André (Org.). Crítica da divisão do trabalho. São Paulo: Martins Fontes, 1980.

SALM, Claudio. Tecnologia e emprego. In: SALM, Claudio et al. Não há vagas: emprego urgente. Curitiba: IPARDES, 1984.

SOBRINHO, Guilherme Xavier. Força de trabalho e capacitação tecnológica em um segmento recente da indústria: as empresas de automação industrial no Rio Grande do Sul. Brasília: SEsı, 1995.

SOUSA, Nair Heloísa Bicalho de. A experiência da exclusão e da rebeldia na construção civil. 1994. Tese (Doutorado em Sociologia) - Instituto de Filosofia, Letras e Ciências Humanas, Universidade de São Paulo, São Paulo, 1994.

TELLES, Vera da Silva. A experiência da insegurança: trabalho e família nas classes trabalhadoras urbanas em São Paulo. Tempo Social, v.4, n.1-2, p.53-93, 1992.

WEBER, Max. A ética protestante e o espírito do capitalismo. 7.ed. São Paulo: Pioneira, 1992.

ZALUAR, Alba. A máquina e a revolta: as organizações populares e o significado da pobreza. São Paulo: Brasiliense, 1985. 


\section{Abstract}

The text analyzes if it is possible to affirm that work society is in its end, or if we are facing reducionist and uncertain analyzes of the terms involved in debate. The conclusion points to the permanence of work as fundamental category to the understanding of individual actions in society, not evidencing the end of work society, but its modification.

Key-words:work, society of work, house holder, unemployment, capitalism. 